\title{
Analyzing Stakeholder Water Source Preference Based upon Social Capital: a Case Study of the Fajr Jam Gas Refinery in Iran
}

\author{
Omid M. Ghoochani ${ }^{1} \cdot$ Mona Dorani $^{1} \cdot$ Mansour Ghanian $^{1} \cdot$ Matthew Cotton $^{2}$
}

Received: 28 April 2017 /Revised: 28 August 2017 / Accepted: 30 August 2017 /Published online: 14 September 2017

(C) Springer Nature Singapore Pte Ltd. 2017

\begin{abstract}
Gas refineries are among the most water-intensive industries in the world. The Fajr Jam gas refinery is one such example, located in the southern Iran. The indiscriminate use of aquifer resources for this highly profitable industry creates tragedy of the commons effects, causing significant environmental controversy and threatening the long-term water security of the region. It behooves decision makers, therefore, to examine a broad range of adaptive water management strategies for this industry. The implementation of such strategies requires understanding the preferences and potential conflicts that may emerge among competing stakeholder interests. This quantitative social scientific study examines stakeholder preferences among water management options through the lens of social capital. Elite stakeholder representatives (including agricultural organizations, governmental organizations, the Water, and Power Authority, Department of Health, Bureau of Water and Wastewater) were canvassed through a survey instrument using paired comparisons. Data were analyzed using Expert Choice software and an analytic hierarchy process technique. The results show that accountability is the
\end{abstract}

Mansour Ghanian

m_ghanian@yahoo.com

Omid M. Ghoochani

Mehrab.omid@gmail.com

Mona Dorani

Dorani.edu@gmail.com

Matthew Cotton

Matthew.cotton@york.ac.uk

1 Department of Agricultural Extension and Education, Ramin Agriculture and Natural Resources University of Khuzestan, Ahvaz, Iran

2 Department of Environment, University of York, York, UK main criterion for selecting the best water sources and ranked first with the Eigenvector 0.62. Also, the results show that the least important criterion was social cohesion with the Eigenvalue 0.033 . The criteria of partnership and trust ranked as two and three with Eigenvalues 0.215 and 0.133 , respectively. The results indicate that the construction of salt water transmission from the sea $(A=0.240)$ is the preferred option among other alternatives, and this is confirmed by sensitivity analysis.

Keywords Water resource preference $\cdot$ Jam gas refinery . Iran $\cdot$ Petrochemicals industry $\cdot$ Multi-stakeholder environmental management $\cdot$ Social capital

\section{Introduction}

Iran holds the third largest known oil reserves and the second largest natural gas reserves globally [1]. It also harbors a petrochemical industry that produces 42.5 million tons of basic chemicals, fertilizers, polymers, feedstock, and fuels annually [2]. Water is a critical component of petrochemical industry operations, with large water volumes used in fuel production primarily for processing and cooling. Based upon global averages, crude oil refineries require an average 5060 gal of water per barrel of crude during production. Refinery water consumption is, however, differentiated by the manufacturing process, alongside the level and types of technology used. Refineries use water for making petroleum products by vapor, for transfer of temperature, transfer of raw materials or waste products, and for mechanical activities. In oil exploration and production, water consumption depends on the source and location of the fossil fuel resource, the recovery technology, and the amount of produced water re-injected for oil recovery [3]. 
With a recent downturn in global oil and gas prices, downstream producers (specifically refineries) are increasingly looking to reduce their operating costs. Water efficiency is a key component of this cost saving. However, in many refineries, water use efficiency is poor, due primarily to technological limitations and outdated water management practices. Moreover, underground water from aquifers and groundwater sources are commonly used for domestic, industrial, and irrigation purposes in Asian countries. However, overexploitation of these sources severely jeopardizes water supply and water quality [4]. This threatens regional water security and increasing energy requirements for pumping technologies. The depletion of aquifers and other ground water sources can have secondary environmental effects such as land subsidence. Therefore, there are both operational and environmental benefits to the identification of alterative water sources in such cases [5]. In our Iranian case study, the Tehran Oil Refining Company began in 2014 an annual transfer of 20 million cubic meters of water from treated wastewater and sewage treatment plant water to restore about $60 \%$ of drinking water to the supply system. The Jam gas refinery is one of the largest gas refineries in Iran, located in Jam City, Bushehr Province. In total, the value of water used in oil refining is 4-20 times more profitable than comparative use in the agricultural sector. However, the refinery has used underground water of the Plain of Jam Township within its production system, severely depleting the resource. This requires an immediate remediation action to prevent total underground water depletion to the affected area. Thus, policy-makers are confronted with the problem of balancing economic gains from fossil fuel products against water stress-related socioeconomic and environmental impacts.

In the academic and policy literatures on assessing water resource options, by far the most commonly used tool is that of multiple criteria analysis (MCA) - a body of assessment techniques which rank or score the performance of alternative decision options against multiple criteria (typically measured in different units). This technique is common to water management practice because of the competing objectives commonly identified. Yet the criteria used for assessment must be evaluated against performance measures, and so commonly used criteria of assessment tend to be aspects such as computational efficiency, explicitness of trade-offs, and the quantity of useful information supplied [6]. Yet there is a growing recognition of the need to move beyond these explicitly quantitative performance measures to assess and integrate so called soft social factors, preferences, and values into water resource management practice, and to understand different values and preferences from the "bottom up," i.e., through empirical research into stakeholder preferences [7].

As is common in contested environmental resource management processes, a socially and environmentally acceptable solution requires the negotiation of multiple stakeholder interests among dependent businesses, regional and national governments, citizen-stakeholder representatives, third sector organizations, and environmental protection groups. In this study, we define stakeholders under a commonly held definition as those individuals or groups with a specific interest in the outcome of decisions, or those that will be directly or indirectly affected by the achievement of petrochemical industry organization objectives [8]. We assume that under conditions of resource management decision-making, there will be conflicts of interest among competing worldviews. Overcoming conflict and reaching (some degree) of consensus among competing water management outcomes are a key criterion of the Jam gas refinery's continued economic success, environmental responsibility, and its social license to operate within the region [9]. This is true, not only for the Jam gas refinery, but for the oil and gas sector world-wide, and so our proposed methodology has applications beyond our case study. The role of stakeholder perspectives has been recognized as an influential factor in both the social acceptance of new technologies and of broader policy success $[10,11]$.This is specifically true for adaptive water resource management solutions [12-15]. As Sharp [16] asserts, there is a growing move away from unseen technical fixes to water management problems, towards more participatory and stakeholder engagement-led approaches. Developing tools to assess stakeholder preference is, therefore, an important research priority. It is necessary to provide tools for effective stakeholder engagement in order to ensure equitable and socially acceptable water resource management outcomes.

Successful adaptive water management from an engagement-led perspective must approximate the diversity of positions and interests and thus increase the practical likelihood of acceptability, implementation, and effectiveness of proposals [17]. Multi-stakeholder appraisal approaches to environmental management and sustainability problems have grown exponentially since the early 1990s [8]. Managing effective stakeholder appraisal of technological options requires both a representative (or at least diverse) and selection of actors that support competing interests [18]. With stakeholder diversity, however, come issues of mutual trust, competition, and conflict resolution. Where consensus (or at least a lack of protracted disagreement) is required in water resource management, representative interests must build trust, social learning, and cohesion towards shared goals, and have buy-in to the process (i.e., participate with one other and have accountability in reaching collective decisions). To this end, we examine the issue of water source choice as a matter of collective action between competing stakeholder interests. We specifically employ the concept of social capital as a key factor in the success of water management outcomes. We presuppose that social relations of trust, shared and collective norms, and networks of association represent the means through which a common and agreed strategy can be upheld among competing stakeholder interests [19-21]. 
To summarize: our principal research objective is to select among water resource management options for the Jam gas refinery case by examining multiple stakeholder perspectives through a social capital theory framework.

\section{Theoretical Framework}

In this study, our underlying assumption is that socio-cultural factors shape the way individuals perceive alternative water resource strategies. The basis for this assertion lies in Bisung and Elliott's (2014) work, exploring a framework linking social capital with community management of water resources. They argue that social capital influences water management practice by shaping collective action, knowledge, attitudes, and behaviors [22]. At its heart, social capital offers a route to sustainable management and governance of common pool resources [23]. Stemming from Hardin's (1968) Tragedy of the Commons ( $\mathrm{ToC}$ ) model, we presuppose that water management is a common pool resource depletion and degradation issue. This is because water resources are shared collectively under conditions where the benefits of water extraction are reaped by an individual (or single group within the collective), leading individuals (or in this case profit-making organizations) to take actions that degrade the resource over the longer term [24]. Though Hardin argued that resolution of ToC problems involves mutual coercion, mutually agreed upon, in order for collective action to preserve resource quality (and in this case, water quantity), Ostrom critiques that governing the commons is dependent less upon coercion, and more upon agreement. Whereas Hardin argued for state control or privatization of the resource as the primary means to protect against common pool resource degradation, Ostrom advocates an alternative approach: critiquing Hardin's assumption that the users of the resource will not communicate the problem to one another and try to a reach an agreement about how to manage the resource in such a way as to avoid common pool resource degradation. Ostrom advocated a system of resource management involving self-organized governance systems (including collaborative, multi-stakeholder environmental management) dependent upon effective communication, trust and reciprocity - which this study, through its measurement of social capital within stakeholder networks attempts to assess in order to improve water management practices [25]. It is necessary, therefore in our research, for group boundaries to be defined: rules that govern water use must meet local needs and conditions, rules about resource use are mutually agreed upon and participatory, and dispute resolution and sanctions can be put in place [25]. In order for this to happen effectively, social rules, norms, and behaviors within common pool resource management need to be understood, and social capital provides a framework or 'lens' through which these issues can be explored.
Social capital is a broad concept, one that has proven both difficult to define and difficult to measure [26]. Though traced to Hanifan's work [27] in the early twentieth Century, the modern sociological concept of social capital can be traced to Jacobs's (1961) description of relational resources within a community and family, and its later popularization following Putnam's Bowling Alone analogy [19]. Using the economic analogy of capital, social capital is conceptualized as a resource that can be accumulated or drawn upon in times of need. Unlike traditional tangible resources (e.g., financial or human capital), social capital is distinctive in that it exists in the structure of relationships between actors, and is, therefore, jointly owned [28]. Social capital, unlike other capital resources, is not physically tradable, but is an emergent phenomenon from the interaction of social practices and shared norms and values. Though intangible and difficult to quantify, harnessing social capital has the potential to offset other capital costs, such as those associated with organizational governance and operational overheads. Alternatively, it has been described as the factors that "glue" society together [29] and defined as "the social connectedness of a community that enables people, organizations, and communities to work together collaboratively for mutual benefit" [30]. Moreover, because individuals can draw from social capital in their communities, it can operate at both an individual and community level [31].

Despite a lack of conceptual consensus, three key types of social capital are commonly cited [32]. Firstly, bonding social capital represents close personal ties within groups, such as families and friends. Second, bridging social capital represents loose ties between people who may or may not share similar characteristics or networks (such as workmates and acquaintances). Third, linking social capital reflects relationships that reach across explicit, formal, or institutionalized power gradients in society. Collectively, these forms of social capital are productive, self-reinforcing and cumulative, and if harnessed effectively can ultimately improve economic performance. Social capital enables participants to act effectively and to pursue shared objectives (and thus is not always socially "positive" - oppressive or criminal networks can harness social capital as well). From an organizational perspective, harnessing these collective social capital resources is a key factor in effective collaborative governance, in stakeholder engagement and in maintaining a social license to operateessentially a trust relationship with the community in which it operates [33]. Gaining social capital can potentially decrease the financial cost of operation of an action [34], and this is particularly true in cases where operations invoke controversy-such as the case in contested environmental management disputes [35-37].

Effective stakeholder involvement can build social capital within and among an organization's stakeholder networks. Building social capital ensures that stakeholders buy into 
shared objectives, management plans and organizational strategies. Building a stock of social capital will likely increase their willingness to contribute to the achievement of such objectives [38]. Though widely recognized as important to stakeholder management, definitions of social capital are fluid and contested. There are, however, a number of recurrent themes that we identify: namely trust, social cohesion, accountability and participation [39-42]. The aim of this research is to define which among these social capital factors have the most impact upon water source preference. Also, we aim to evaluate this in relation to indices for the aforementioned four concepts.

Trust, in this context is the confidence held within a stakeholder network that others will act on commitments reliably and with reciprocity. It is a core mechanism through which social capital is mobilized for collective action towards a common goal [43]. Trust is dependent upon characteristics of individuals and their setting, including institutions, the nature and extent of social networks, and individual characteristics. Trust may also be related to an individual's tolerance for risk, since trusting another individual may, in many cases, carry risks [44].

Social cohesion, stemming from the work of the sociologist Durkheim, relates to loyalty and solidarity as necessary components for any society [45]. Durkheim (1893) argued that there is no clear definition of the concept of social cohesion and it cannot be measured directly. In his view, "joint loyalty and solidarity" are key factors in social cohesion. According to Durkheim, there are two types of solidarity: mechanical solidarity and organic solidarity. Mechanical solidarity refers to the traditional uniformity of collective values and beliefs and organic solidarity refers to the modern relationships between people that are able to work together [46]. Therefore, social cohesion is taken into account as a precondition towards the use of social capital and development. The feeling of "being together" with other people, feeling safe [47], and having a sense of belonging, inclusiveness and legitimacy is also included in this concept [48]. In practice, development organizations such as the World Bank consider social cohesion as important for economic prosperity and sustainable development within communities [49].

Our third component of social capital theory is accountability. Humans are fundamentally social animals; interaction with others and a sense of shared responsibility within social groups is deeply important. Accountability is the means by which humans accept responsibility (or are held responsible) for their moral actions towards others within and between social groups. This leads to our fourth concept of participation - a concept that is widely theorized and applied in stakeholder management processes. It is, broadly speaking, the point at which civil society and citizenstakeholder interests are brought into decision-making process within environmental management. It is, in essence, a form of social interaction within civil society [50]. This includes the involvement of organizations, associations or other volunteer groups, and those activities which through them, citizen stakeholders become involved in community affairs and are directly or indirectly involved in shaping social life [51]. Participation can be offered at two levels. The first is mental participation, which tend to be the result of social participation and other factors underlying people's sense of trust. The second is at a more objective level. Participation is also the social practices of engagement with fellow members of social networks, either through formal "invited" engagement processes instigated by authorities seeking input from stakeholder on proposed policies and plans, or else uninvited "bottom up" participation of stakeholders seeking to influence the outcomes of such policies and plans from the outside [52]. It is this collective action of invited and uninvited social participation that is an important component of social capital [53].

As mentioned, social capital generally refers to the collectively owned asset which resides in and is derived from durable relationships between actors and/or social units [54]. It is reported to be a productive resource that boosts organizational growth and innovation performance [55], potentially leading to mutually beneficial outcomes including better group communication and knowledge sharing and enhanced use of intellectual capital [56]. Social capital mobilization can also

Table 1 The criteria and indicators

\begin{tabular}{|c|c|c|}
\hline Criteria & Code name & Indicator \\
\hline \multirow[t]{4}{*}{ Social participation } & M1 & $\begin{array}{l}\text { Local managers engage in the process of } \\
\text { water resources management }\end{array}$ \\
\hline & M2 & $\begin{array}{l}\text { The use of local engineers and experts in } \\
\text { the selection and management of } \\
\text { water resources }\end{array}$ \\
\hline & M3 & $\begin{array}{l}\text { Stakeholder partnership in the operation } \\
\text { and maintenance }\end{array}$ \\
\hline & M4 & $\begin{array}{l}\text { Official working of various agencies } \\
\text { working in water resource } \\
\text { management }\end{array}$ \\
\hline \multirow[t]{3}{*}{ Trust } & A1 & $\begin{array}{l}\text { Trust between government agencies and } \\
\text { organizations to each other }\end{array}$ \\
\hline & $\mathrm{A} 2$ & Trust between stakeholders \\
\hline & A3 & $\begin{array}{l}\text { Local self-government bodies of the } \\
\text { people }\end{array}$ \\
\hline \multirow[t]{2}{*}{ Social cohesion } & AN1 & $\begin{array}{l}\text { Coordination between government } \\
\text { agencies and stakeholders }\end{array}$ \\
\hline & AN2 & $\begin{array}{l}\text { Coordination among government } \\
\text { agencies }\end{array}$ \\
\hline \multirow[t]{5}{*}{ Accountability } & MS1 & $\begin{array}{l}\text { Disregard for executives and } \\
\text { high-ranking officials in matters re- } \\
\text { lated to water resources }\end{array}$ \\
\hline & MS2 & $\begin{array}{l}\text { Responsibility governmental } \\
\text { organizations on the protection of } \\
\text { water resources }\end{array}$ \\
\hline & MS3 & $\begin{array}{l}\text { The development of the water } \\
\text { distribution network in the future }\end{array}$ \\
\hline & MS4 & $\begin{array}{l}\text { Risk or risks associated with the } \\
\text { destruction of personal intentions }\end{array}$ \\
\hline & MS5 & $\begin{array}{l}\text { Environmental degradation caused by } \\
\text { water resources }\end{array}$ \\
\hline
\end{tabular}




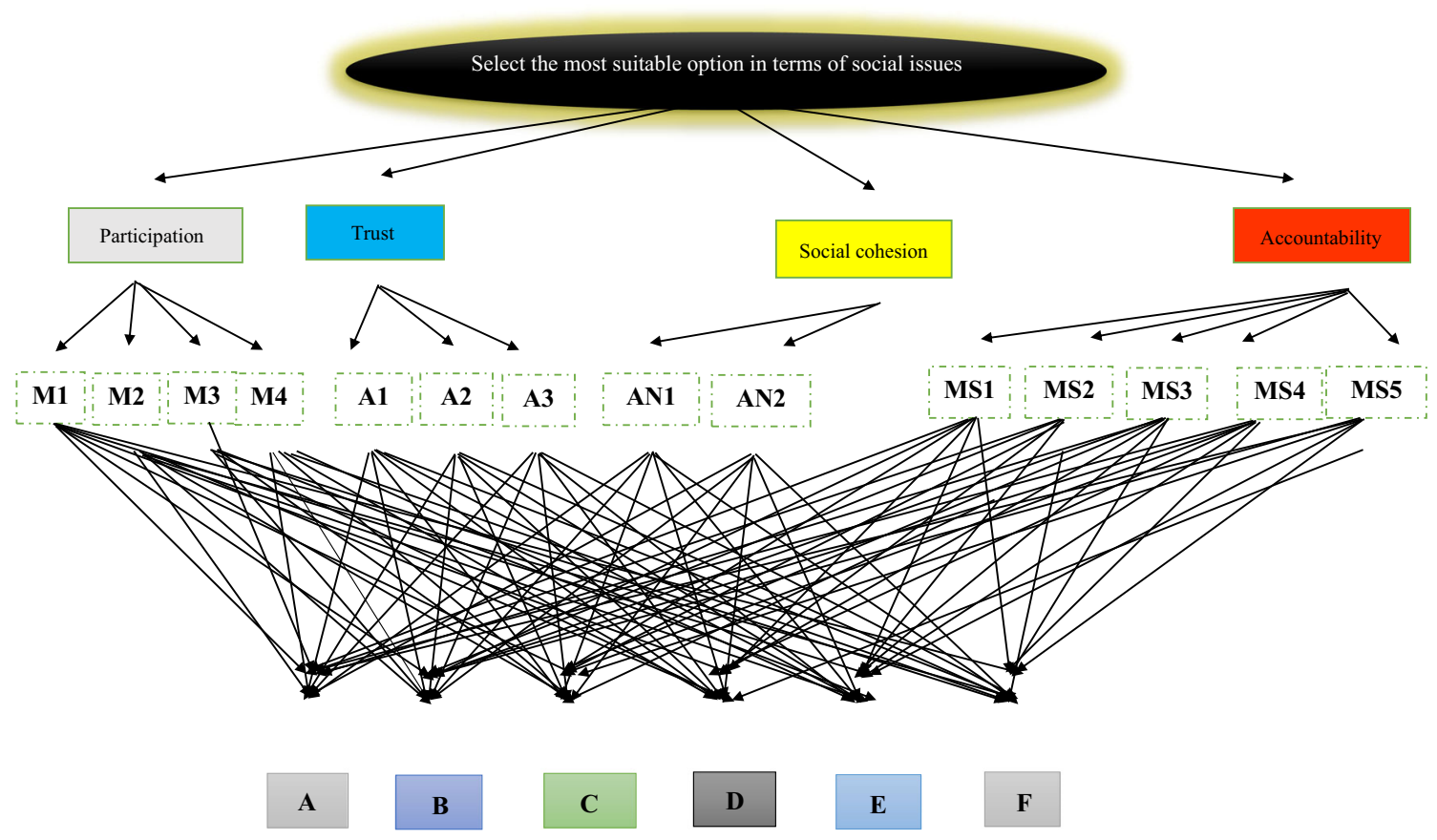

Fig. 1 Model of AHP to select the most suitable water source based on social capital

potentially alleviate a broader scarcity of resource and other capital constraints in peripheral communities [57]. In fact, the interplay of economic and social capital is a core aspect of social life. Its value for this research is that a social capital lens can be used to define the most appropriate option to facilitate the extraction of water with the least amount of stakeholder conflict, based upon the assertion that where more social capital exists among a range of stakeholders around a preferred water management option, that this will be the one which stimulates the least conflict, thus having the greatest opportunity for project success.

\section{Methods}

In defining stakeholder preference for water resource management options, we adopt a quantitative social scientific approach based upon a case study of the Jam City gas refinery - the largest in Iran. The study population was identified

Table 2 The pairwise comparison scale [62]

\begin{tabular}{ll}
\hline $\begin{array}{l}\text { Intensity of } \\
\text { importance }\end{array}$ & Definition \\
\hline 1 & \\
3 & Equal importance both element \\
5 & Weak importance one element over another \\
& Essential or strong importance one element over \\
another & Demonstrated importance one element over another \\
9 & Absolute importance one element over another \\
$2,4,6,8$ & Intermediate values between two adjacent judgments \\
\hline
\end{tabular}

through purposive sampling. It consisted of ten "elite" participants in governmental agencies. These include the Power and Water Authority, Department of Health, Agricultural organizations, the Water and Sewage Department, and the Department of the Environment in Bushehr Province. Collectively, these are the decision-makers for water allocation and are the ones that perform the paired comparisons. The study had two separate phases. In the first phase, we surveyed the literature on social capital and water management respectively, to define the appropriate criteria and indicators. The criteria and indicators are shown in Table 1.

In the second phase, we consulted four technical experts from the engineering company of Sazab Pardazan, to identify the range of technical options available for the Jam gas refinery. The selected water sources are as follows which used for paired comparisons to select among options:

A: A sea water transmission line from the Persian Gulf to Jam City and establishing desalination technology

B: Exploration for underground water sources, including groundwater/wells

C: Artificial feeding and restoration of existing wells

D: Supplying water from the river dam of Gavbandi

E: Purification of urban sewage

F: Calculate the water requirement of residential towns' refinery and recycling water used.

Based on the criteria and indicators, the analytic hierarchy process (AHP) model provided and the pairwise comparison matrix was established (Fig. 1). Then weights related to the 
Fig. 2 Factors for prioritizing water source preference

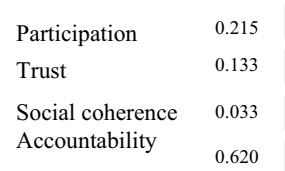

Inconsistency $=0.02$ options and criteria were determined by an expert review [58]. In this step, the authors used a linear model based on the criteria in line with those employed in other environmental/ resource management case studies [59-61]. The elements of a particular level are compared pairwise with respect to a specific element in the immediate upper level. A judgment matrix was formed and used for computing the priorities of the corresponding elements. First, each criterion was compared pairwise with respect to the goal. The judgment matrix, denoted as $\mathrm{A}$, was formed using the comparison. Therefore, let $A_{1}$, $A_{2}, \ldots, A_{n}$, be the set of stimuli. The quantified judgments on pairs of stimuli, $A_{i}, A_{j}$, are represented by:

$A=\left[a_{i j}\right] i, j=1,2, \ldots, n$

The comparison of any two criteria $C_{i}$ and $C_{j}$ with respect to the goal is made using the questions of the type: of the two criteria $C_{i}$ and $C_{j}$, which is more important and by how much? Saaty (1980) suggests the use of a 9-point scale to transform the verbal judgments into numerical quantities representing the values of $a_{i j}$. Table 2 lists the definition of the 9-point scale. A larger number assigned to the pairwise comparisons means larger differences between criteria levels. The entries $a_{i j}$ are governed by the following rules:

$a_{i j}>0, a_{i j}=\frac{1}{a_{i j}}, a_{i j}=1$ for all $i$

This scale can be applied with ease to criteria that can be defined both numerically and non-numerically. The relative importance scale is presented. The participants were instructed to specify their judgments of the relative importance of each criterion towards achieving the overall goal, and so a questionnaire was devised to assess stakeholder preferences among water resource management options using pairwise comparison. Based upon the weighted value that the stakeholders finally assigned, the geometric mean value was used to compute decision-making community scores from all experts in order to formulate the weighted values selected for choosing the best water sources for the Jam gas refinery.

Having recorded the numerical judgments $\mathrm{a}_{\mathrm{ij}}$ in the matrix A, the problem is then to recover the numerical weights $\left(W_{1}\right.$, $W_{2}, \ldots, W_{n}$ ) of the alternatives from this matrix. In order to do so, we use the following equation:

$\left[\begin{array}{ccc}a_{11} & \cdots & a_{1 n} \\ \vdots & \ddots & \vdots \\ a_{n 1} & \cdots & a_{n n}\end{array}\right] \cong\left[\begin{array}{ccc}w_{1} / w_{1} & \cdots & w_{1} / w_{n} \\ \vdots & \ddots & \vdots \\ w_{n} / w_{1} & \cdots & w_{n} / w_{n}\end{array}\right]$

We multiply both matrices in Eq. (3) on the right with the weights vector $W=\left(W_{1}, W_{2}, \ldots, W n\right)$, where $W$ is a column vector. The result of the multiplication of the matrix of pairwise ratios with $W$ is $n W$, hence it follows:

$A w=n W$

This is a system of homogenous linear equations. It has a non-trivial solution if and only if the determinant of $A$ - $n I$ vanishes; that is, $n$ is an eigenvalue of $A$. $I$ is an $n \times n$ identity matrix. Saaty's method (Saaty, 1980) computes $W$ as the principal right eigenvector of the matrix $A$; that is,

$A w=\lambda_{\max } W$

where $\lambda_{\max }$ is the principal eigenvalue of the matrix $A$. If matrix $A$ is a positive reciprocal one, then $\lambda_{\max } \geq n$ (Saaty, 1990). If $A$ is a consistency matrix, eigenvector $X$ can be calculated by:

$\left(A-\lambda_{\max } I\right) X=0$

Here, using the comparison matrix, the eigenvectors were calculated by Eqs. (5) and (6). Then the consistency test is performed. The eigenvector method is the most popular method to estimate a priority vector [63]. Therefore, this reflects the
Fig. 3 Key indicators of the participation factor

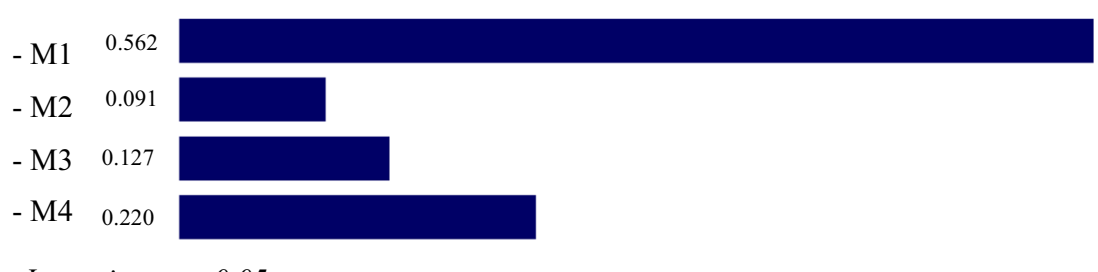

Inconsistency $=0.05$ 
Fig. 4 Key indicators of the trust factor

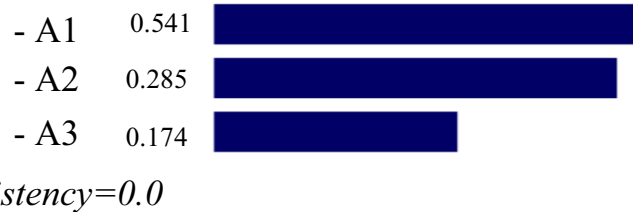

importance of this criterion across all stakeholder participant perspectives.

Expert Choice Software (ECS) was used to achieve the goal of the present study, i.e., the preferred water resource management strategy for the Jam gas refinery.

\section{Results}

The results of paired comparison between the criteria of social capital are presented in Fig. 2. This shows that accountability is the main criterion for selecting the best water source and it is ranked first with the eigenvector 0.62 . The least important criterion was social cohesion with the eigenvalue 0.033 . The criteria of partnership and trust ranked as two and three with the eigenvalues 0.215 and 0.133 , respectively.

The following sections examine the indices of different social capital dimensions with respect to water source preference:

\section{Partnership}

Figure 3 shows the result of paired comparisons of indicators for the partnership factor. Figure 3 shows that partnership is the most preferred indicator by local administrators in the process of water resources management (M1) (0.562). This suggests that local administrators' collaboration is the most important criterion in selecting water sources among other partnership criteria. Also, the indicator of "The use of local engineers and experts in the selection and management of water resources" is the least important in water source selection within the partnership factor (M2) (0.091).

\section{Trust}

The results of paired comparisons between trust's indicators are presented in Fig. 4. As shown in Fig. 4, the indicator of "trust between organizations and government agencies" is the most important to select a water source strategy $(\mathrm{A} 1=0.541)$. This reflects the importance of this indicator across the viewpoints of all stakeholders sampled. According to the results, the least important indicator was "local government" with the eigenvalue 0.174 .

\section{Social Cohesion}

Results of paired comparisons between social cohesion's indicators are presented in Fig. 5. As shown in Fig. 5, the indicator of "coordination between government agencies and stakeholders" is the most important to select a water source strategy $(\mathrm{AN} 1=0.544)$. This reflects the importance of this indicator across all stakeholder perspectives.

\section{Accountability}

Results of paired comparisons between accountability's indicators are presented in Fig. 6. As shown in Fig. 6, the indicator of "disregard for executives and high-ranking officials in matters related to water resources" is the most important to select water source (MS1 $=0.453)$. This reflects the importance of this indicator in the viewpoint of all stakeholders. According to the results, the least important indicator was "environmental degradation caused by water resources" with the eigenvalue (MS5 = 0.048).

\section{Social Capital and Water Source Preference}

The final scores for each water source alternative based on the relative weight of criteria and indicators were calculated. Then based on the final score, the most preferred water source was selected. Figure 7 shows the final results of water source preference.

We find that "the construction of salt water transmission from the sea" ( $A=0.240)$ is the most preferred option among other alternatives, followed by alternatives "water use
Fig. 5 Key indicators of the social cohesion factor
- AN1 0.544

- AN2 0.456

Inconsistency $=0.0$ 
Fig. 6 Key indicators of the accountability factor
- MS1 0.453

- MS2 0.196

- MS3 0.109

- MS4 0.195

- MS5 0.048

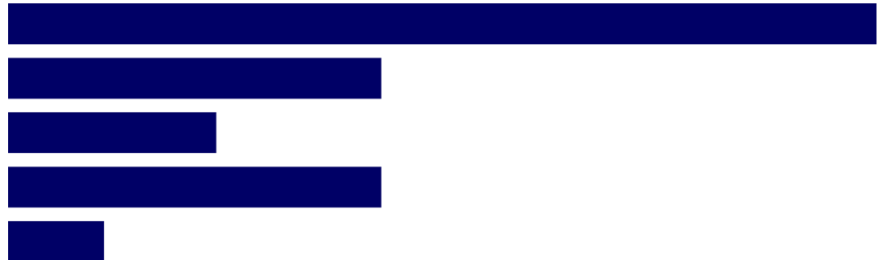

management" (F) and "purification of urban sewage" (E) in second and third place.

One of the most important indicators of judgment in relation to the accuracy of model results is the use of sensitivity analysis. The results of sensitivity analysis show how the options are ranked in comparison to their alternatives. In model building using the analytical hierarchy process, sensitivity analysis is a crucial step in determining if the solution is implementable and robust [64]. Sensitivity analysis is performed to test the stability of the priority ranking. Therefore, this work illustrates how the AHP model would be implemented to help engineers determine the manufacturing process yield quickly and effectively [65]. The expert choice software has some modes of sensitivity analysis, including performance, dynamics, gradient, and head-to-head sensitivity analysis. The results of the sensitivity analysis model to choose the best alternative shown in Figs. 8, 9 and 10.

\section{Dynamic Sensitivity Analysis}

This sensitivity analysis is used for the dynamic changing of the importance of factors, i.e., it is used to determine how these changes will affect the selection of alternatives. Therefore as per Fig. 8, under normal weighting, the factors of participation, trust, social cohesion, and accountability are equal to $0.215,0.133,0.033$, and 0.620 , respectively. According to these weights, option A is selected.

\section{Performance Sensitivity Analysis}

The sensitivity analysis shows how the alternatives ranked compare to the other alternatives. As can be seen in Fig. 9, option A started from 0.75 in the participation factor and increased to 0.95 in the social cohesion factor. The weight of this option was reduced from social cohesion to accountability. The weight of this option then decreased to about 0.80 in accountability. The right column of the chart shows the total weight of the options. According to the results, option A is ranked first by all factors.

\section{Gradient Sensitivity Analysis}

The gradient sensitivity analysis of the options is shown in Fig. 10. The head-to-head points in the participation factor in option $\mathrm{A}$ and $\mathrm{F}$ is 0.47 . In the trust factor, the head-tohead point of $\mathrm{A}$ and $\mathrm{F}$ is 0.09 . Head-to-head points for the social cohesion factors $\mathrm{A}$ and $\mathrm{F}$ is 0.04 . In the accountability factor, two alternatives of $\mathrm{A}$ and $\mathrm{F}$ overlapped completely.

\section{Discussion}

In order to achieve sustainable development, it is necessary to align economic growth with environmental protection and social cohesion simultaneously. The management of water resources in petrochemical refineries is one of the key areas of unsustainable practice within the manufacturing sector - an issue pertinent (but not exclusive to) Iranian society. In Iran, industrial water usage has increased greatly in the last century, principally due to the profitability of this industry when compared to other competing high water use sectors (specifically agriculture and domestic water consumption). The Jam gas refinery is one of the largest gas refineries in Iran, located in Jam City, Bushehr Province. Its impact upon local water stress is significant for the region. Allocation of water to the refinery must be economically efficient, technically practicable, and socially equitable. Therefore, there is a need for a suitable water allocation system in which water is considered as social and economic commodity [66]; and so determining a socially acceptable water management strategy is a key priority. We assert that water resource management success must inevitably involve the input of multiple stakeholder perspectives and

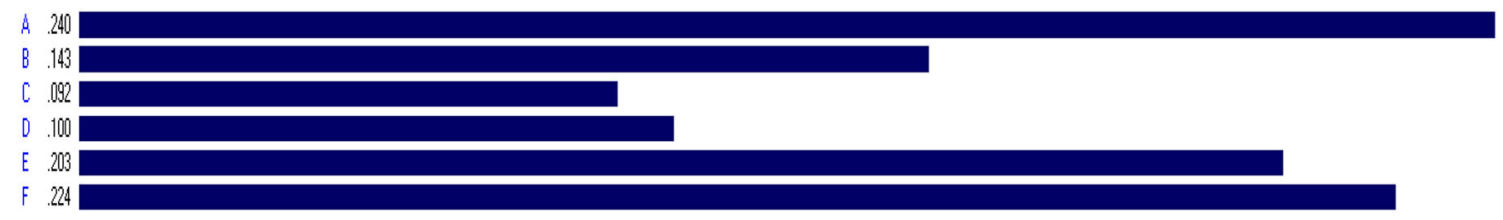

Fig. 7 Selecting the preferred water source 

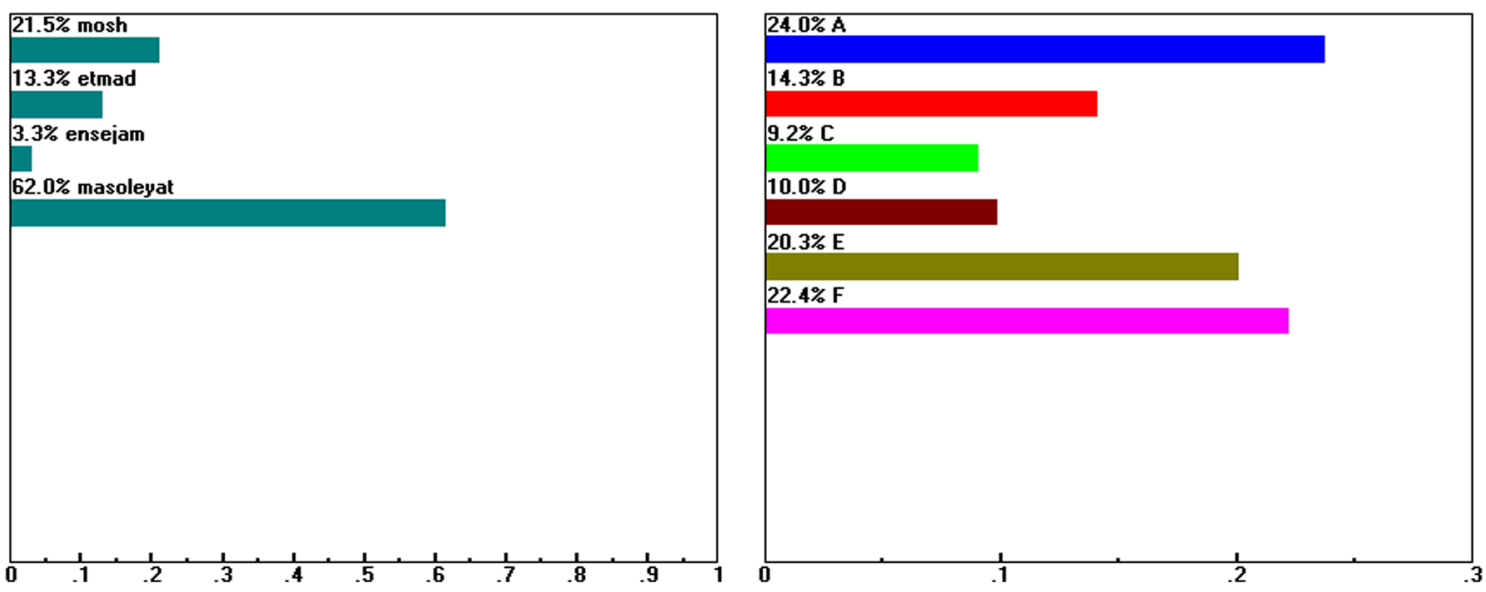

Fig. 8 Dynamic sensitivity analysis charts

preferences. To understand such preferences we use social capital theory because this facilitates an understanding of the most socially acceptable option for water extraction with the least degree of conflict - a factor crucial to project success under conditions where decisions are made in the context of collaborative, multi-stakeholder resource management. Social capital is one component of broader capital resources, which along with human, resource, and financial capital have an overall impact upon economic growth.

At first glance, social capital is commonly overlooked in understanding economic growth, in part because it is difficult to define and measure [26]. However, it plays an effective role in the structure and relationships between individuals, groups, and organizations. Involving stakeholders in water management practices is a key aspect of ensuring project success, with social capital indicators providing a useful tool for differentiating between the social acceptability of different technical options. The purpose of this study was to select the preferred water source based upon a quantitative evaluation from the perspectives of different elite stakeholder participants using social capital criteria to differentiate between options and to demonstrate the effectiveness of such a method to other resource management options assessment processes. Despite there being no single definition of social capital to adhere to, we have derived core components of participation, trust, social coherence, and accountability as measurable indicators from our assessment of the sociological literature. The results of paired comparisons showed that among these four factors of social capital it is accountability that is deemed the most important factor.

In terms of preferred options, transmission of seawater from the Persian Gulf to the Jam Township has been identified by experts as the first priority among the competing options. We then assessed this using sensitivity analysis because this is a reliable indicator of judgment in relation to the accuracy of model results. According to all sensitivity analysis models, this alternative was considered as the first priority. This alternative is likely to generate the least conflict of interest between competing stakeholders; however, this option has high financial capital intensity and supporting infrastructure

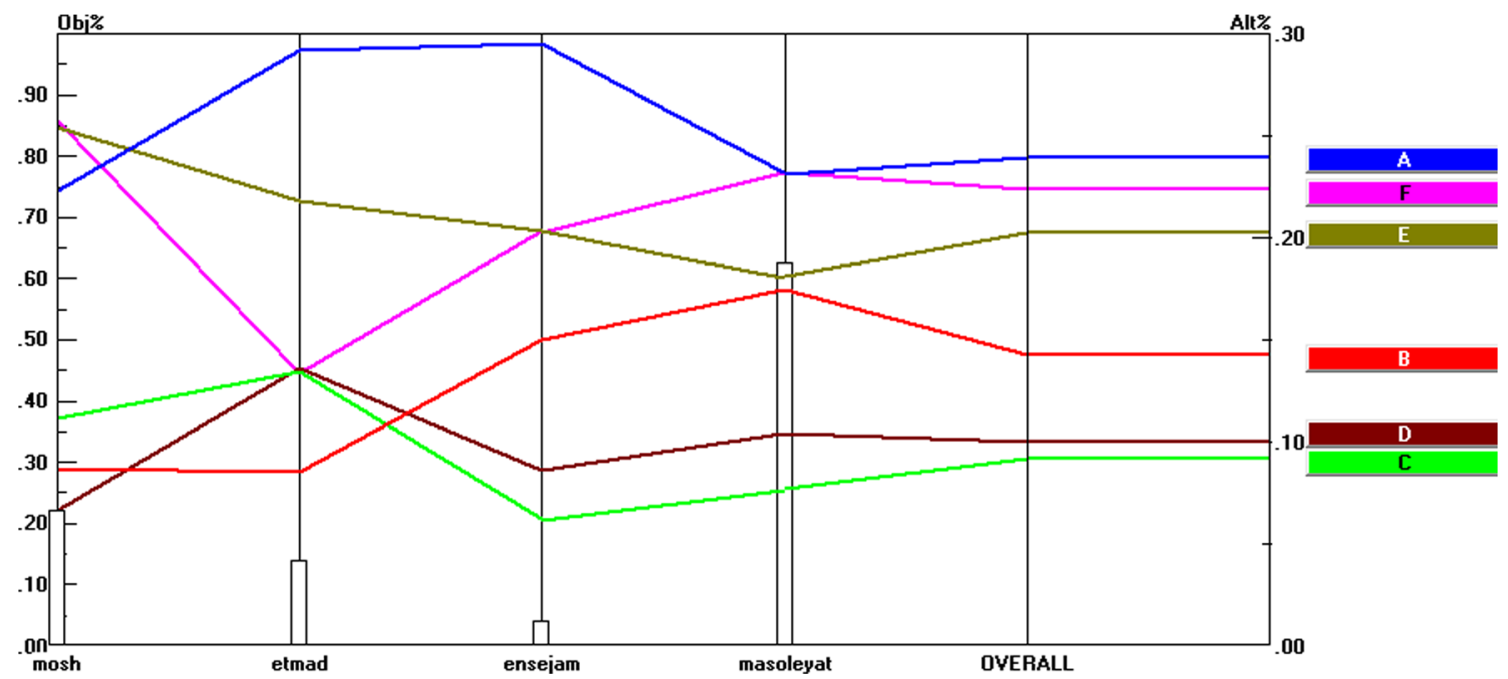

Fig. 9 Sensitivity analysis performance 
Fig. 10 Gradient sensitivity analysis
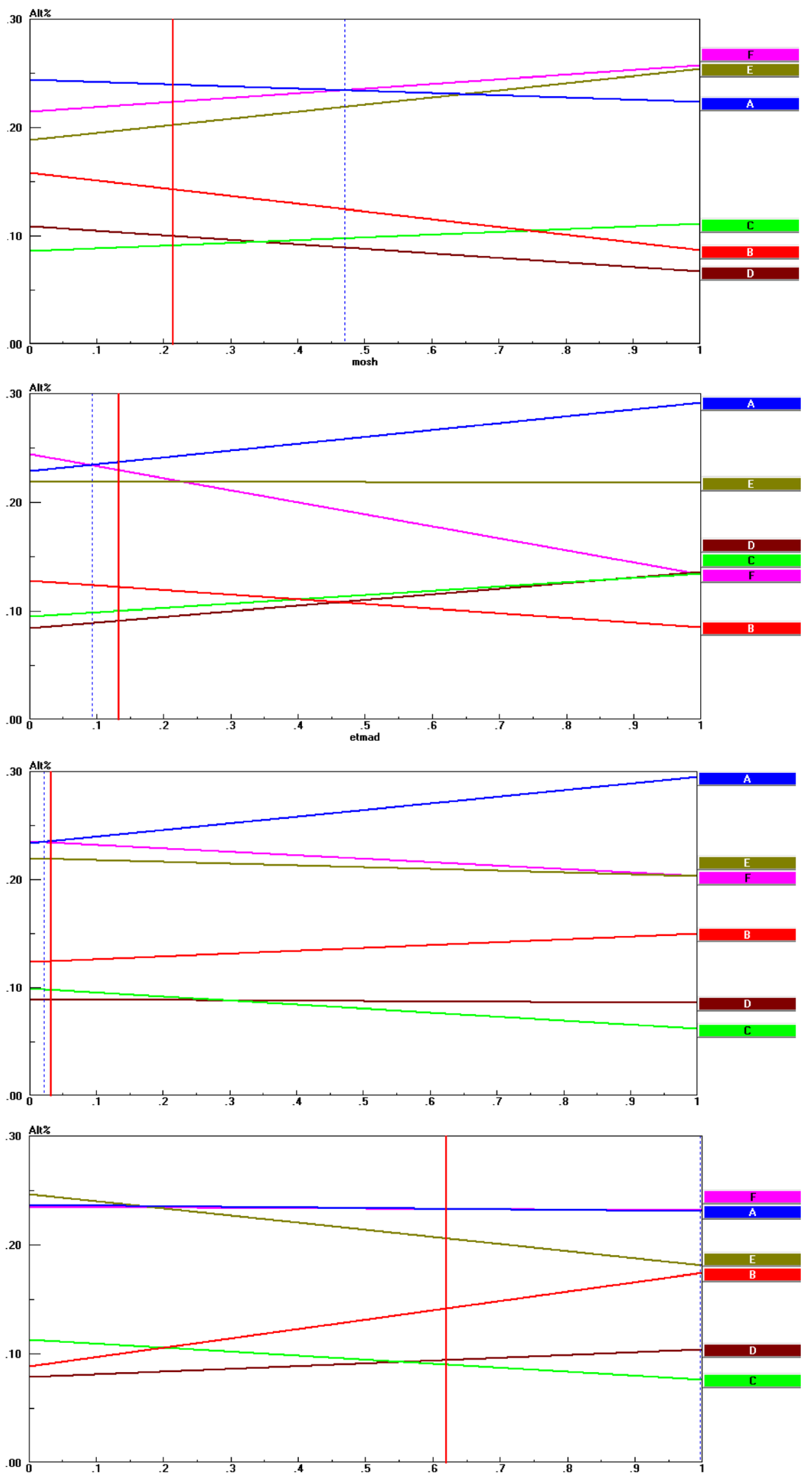
requirements. Based on the research and expert input in the first phase of the study, we establish that seawater transmission requires the construction of a $40-\mathrm{km}$ pipe and three desalination stations with the capacity of $17,000 \mathrm{~m}^{3}$ water. Also, it should be noted that this option can have negative consequences on the regional ecosystems due to the accumulation of salt from seawater. Seawater transmission also has high capital cost (specifically of desalination plant technology), but also suffer high maintenance costs over the lifecycle of their operation. A sea water desalination option would, therefore, require comprehensive research into the regional ecosystem services, capital costs and socio-economic impacts. The second alternative of improved water efficiency would provide water for Jam gas refinery through calculating the water requirements of nearby residential towns and increasing water recycling domestically, thus easing localized water stress and increasing resource availability for the refinery. Our results show that this option also generates low conflict of interest among the stakeholder participants. More than $2000 \mathrm{~m}^{3}$ water is wasted daily in the region: encouraging greater water use efficiency has a high degree of social acceptance among stakeholder interests. Behavioral management of consumer water consumption practices through economic incentivization is thus advised.

Finally, it should be considered that this study presents a stakeholder preference analysis tool for use in other environmental resource management contexts. In the process of planning major infrastructure projects, achieving options that are both low financial cost and generate low stakeholder conflicts is a high priority. By using this tool (potentially as part of a multi-criteria assessment, or alongside it) it is possible to map social capital indicators across technology options. This has the potential to reduce environmental management conflicts among competing perspectives - improving both the environmental and social performance of plans and projects by revealing options that are likely to generate low social conflict and thus greater levels of public acceptance. Such a method is both easy to administer, using small $n$ respondent sample survey techniques, and yet sufficiently robust to choose among competing options based upon relevant social criteria.

\section{References}

1. Ghabezi R (2012) Financial evaluation of National Iranian Oil Company investment in the south pars. Am J Sci Res 45:76-84

2. Company NP (2014) Iran's Petrochemical Industry Report 2014

3. Wu M et al (2009) Water consumption in the production of ethanol and petroleum gasoline. Environ Manag 44(5):981-997

4. Aghakhani A et al (2014) Comparison of methods to estimate the industrial water demand based on the number of industrial units, number of employees, total area and the infrastructure area. Hygiene Res J 6(2):357-364 (In Persian)
5. Bouwer H (1977) Land subsidence and cracking due to groundwater depletion. Ground Water 15(5):358-364

6. Hajkowicz S, Collins K (2007) A review of multiple criteria analysis for water resource planning and management. Water Resour Manag 21(9): 1553

7. Jensen R, Uddameri V (2009) Using communication research to gather stakeholder preferences to improve groundwater management models: a South Texas case study. J Sci Commun 8(1):1-8

8. Mitchell RK, Agle BR, Wood DJ (1997) Toward a theory of stakeholder identification and salience: defining the principle of who and what really counts. Acad Manag Rev 22(4):853-886

9. Gunningham N, Kagan RA, Thornton D (2004) Social license and environmental protection: why businesses go beyond compliance. Law Soc Inquiry 29(2):307-341

10. Van Eijndhoven JC (1997) Technology assessment: product or process? Technol Forecast Soc Chang 54(2-3):269-286

11. Stirling A (2008) "Opening up" and "closing down" power, participation, and pluralism in the social appraisal of technology. Sci Technol Hum Values 33(2):262-294

12. Mysiak J, Giupponi C, Rosato P (2005) Towards the development of a decision support system for water resource management. Environ Model Softw 20(2):203-214

13. McDaniels TL, Gregory RS, Fields D (1999) Democratizing risk management: successful public involvement in local water management decisions. Risk Anal 19(3):497-510

14. Jonsson A (2005) Public participation in water resources management: stakeholder voices on degree, scale, potential, and methods in future water management. AMBIO: A J Human Environ 34(7): 495-500

15. Morrison K (2003) Stakeholder involvement in water management: necessity or luxury? Water Sci Technol 47(6):43-51

16. Sharp L (2016) Reconnecting people and water: public engagement and sustainable urban water management. Routledge, London

17. Ghoochani OM, Ghanian M, Baradaran M, Alimirzaei E, Azadi H (2016) Behavioral intentions toward genetically modified crops in Southwest Iran: a multi-stakeholder analysis. Environ Dev Sustain 1-21. https://doi.org/10.1007/s10668-016-9879-3

18. Freeman RE, Harrison JS, Wicks AC, Parmar B, De Colle S (2010) Stakeholder theory: the state of the art. Cambridge University Press, Cambridge

19. Putnam RD (1995) Bowling alone: America's declining social capital. J Democr 6(1):65-78

20. Coleman JS (1988) Social capital in the creation of human capital. Am J Sociol 94:S95-S120

21. Fukuyama F (1995) Trust: the social virtues and the creation of prosperity. Free Press, NY

22. Bisung E et al (2014) Social capital, collective action and access to water in rural Kenya. Soc Sci Med 119:147-154

23. Pretty J (2003) Social capital and the collective management of resources. Science 302(5652):1912-1914

24. Jakobsen S (1999) International relations and global environmental change: review of the burgeoning literature on the environment. Cooperation and Conflict 34(2):205-236

25. Ostrom E (2015) Governing the commons. Cambridge University Press, Cambridge

26. Bankston CL III, Zhou M (2002) Social capital as process: the meanings and problems of a theoretical metaphor. Sociol Inq 72(2):285-317

27. Hanifan LJ (1916) The rural school community center. The Annals of the American Academy of Political and Social Science 67(1): $130-138$

28. Al-Tabbaa O, Ankrah S (2016) Social capital to facilitate 'engineered' university-industry collaboration for technology transfer: a dynamic perspective. Technol Forecast Soc Chang 104:1-15 
29. Kawachi I, Berkman L (2000) Social cohesion, social capital, and health. In: Berkman LF, Kawachi I (eds) Social epidemiology. Oxford University Press, New York, p 174-190

30. Lasker RD, Weiss ES (2003) Broadening participation in community problem solving: a multidisciplinary model to support collaborative practice and research. J Urban Health 80(1):14-47

31. Fujiwara T, Kawachi I (2008) A prospective study of individuallevel social capital and major depression in the United States. J Epidemiol Community Health 62(7):627-633

32. Hawkins RL, Maurer K (2009) Bonding, bridging and linking: how social capital operated in New Orleans following Hurricane Katrina. Br J Social Work 40:1777-1793

33. Prno J, Slocombe DS (2012) Exploring the origins of 'social license to operate' in the mining sector: perspectives from governance and sustainability theories. Resour Policy 37(3):346-357

34. Miri G et al (2005) The role of social capital in rural development (case of Sistan). Geogr Reg Dev 14:30-48 (In Persian)

35. Rydin Y, Pennington M (2000) Public participation and local environmental planning: the collective action problem and the potential of social capital. Local Environ 5(2):153-169

36. Castro AP, Nielsen E (2001) Indigenous people and co-management: implications for conflict management. Environ Sci Pol 4(4): 229-239

37. Selman P, Parker J (1997) Citizenship, civicness and social capital in local agenda 21. Local Environ 2(2):171-184

38. Payne GT et al (2011) Multilevel challenges and opportunities in social capital research. J Manag 37(2):491-520

39. Easterly W, Ritzen J, Woolcock M (2006) Social cohesion, institutions, and growth. Econ Polit 18(2):103-120

40. Ritzen J, Easterly W, Woolcock MJ (2000) On "good" politicians and "bad" policies: social cohesion, institutions, and growth. World Bank, Washington DC

41. Veenstra G (2002) Explicating social capital: trust and participation in the civil space. Canadian Journal of Sociology/Cahiers Canadiens de Sociologie 27(4):547-572

42. Uphoff $N$ (2000) Understanding social capital: learning from the analysis and experience of participation. Social capital: a multifaceted perspective. Sociological Perspectives on Development series. World Bank, Washington, D. C., pp 215-252

43. Tavakoli M, Mirzapour S, Shams Puya M (2014) The assessment of social capital components in rural areas of Khoram Abad township. Geogr Dev 39:17-28 (In Persian)

44. Stern MJ, Coleman KJ (2015) The multidimensionality of trust: applications in collaborative natural resource management. Soc Nat Resour 28(2):117-132

45. Levitas R (1996) The concept of social exclusion and the new Durkheimian hegemony. Crit Social Policy 16(46):5-20

46. Fenger M (2012) Deconstructing social cohesion: towards an analytical framework for assessing social cohesion policies. Corvinus J Soc Soc Policy 2:39-54

47. Lindén-Boström M, Persson C, Eriksson C (2010) Neighbourhood characteristics, social capital and self-rated health-a populationbased survey in Sweden. BMC Public Health 10(1):628

48. Spoonley P et al (2005) Social cohesion: a policy and indicator framework for assessing immigrant and host outcomes. Soc Policy J N Z 24(1):85-110
49. Ali AK, Mansur A (2006) Social capital and rural community development in Malaysia. In: Yokoyama S et al (eds) Potential of social capital for community development. Asian Productivity Organization (APO), Japan

50. Claridge T (2004) Designing social capital sensitive participation methodologies. Discussion Papers in University of Queensland, Australia. Available from: http://www.socialcapitalresearch.com/ wpcontent/uploads/2013/01/Social-Capital-and-ParticipationTheories.pdf. Accessed 18 Dec 2014

51. Zukewich N, Norris D (2005) National experiences and international harmonization in social capital measurement: a beginning. In Siena Group meeting, Helsinki

52. Wehling P (2012) From invited to uninvited participation (and back?): rethinking civil society engagement in technology assessment and development. Poiesis Prax 9(1-2):43-60

53. Guillen L, Coromina L, Saris WE (2011) Measurement of social participation and its place in social capital theory. Soc Indic Res 100(2):331-350

54. Adler PS, Kwon S-W (2002) Social capital: prospects for a new concept. Acad Manag Rev 27(1):17-40

55. Maurer I, Bartsch V, Ebers M (2011) The value of intraorganizational social capital: how it fosters knowledge transfer, innovation performance, and growth. Organ Stud 32(2):157-185

56. Tsai Y-H et al (2014) Group social capital in virtual teaming contexts: a moderating role of positive affective tone in knowledge sharing. Technol Forecast Soc Chang 86:13-20

57. Williams D (2006) On and off the 'Net: scales for social capital in an online era. J Comput-Mediat Commun 11(2):593-628

58. Valipour M, Montazar AA (2012) An evaluation of SWDC and WinSRFR models to optimize of infiltration parameters in furrow irrigation. Am J Sci Res 69(2012):128-142

59. Valipour M (2015) Study of different climatic conditions to assess the role of solar radiation in reference crop evapotranspiration equations. Arch Agron Soil Sci 61(5):679-694

60. Valipour M (2013) Increasing irrigation efficiency by management strategies: cutback and surge irrigation. ARPN J Agric Biol Sci 8(1):35-43

61. Valipour M, Mousavi M, Valipour R, Rezaei E (2013) A new approach for environmental crises and its solutions by computer modeling. In The 1st international conference on environmental crises and its solutions, Kish Island

62. Saaty T (1980) The analytic hierarchy process. McGrawHill, New York

63. Brunelli M (2015) Priority vector and consistency. In Introduction to the analytic hierarchy process. Springer. $p$ 17-31

64. Saaty TL, Vargas LG (2013) The logic of priorities: applications of business, energy, health and transportation. Springer Netherlands: Science \& Business Media, Netherlands

65. Chang C-W et al (2007) An application of AHP and sensitivity analysis for selecting the best slicing machine. Comput Ind Eng 52(2):296-307

66. Babel M, Gupta AD, Nayak D (2005) A model for optimal allocation of water to competing demands. Water Resour Manag 19(6): 693-712 